\title{
Choosing and not choosing with and without communication: Experimental results on contract design and selection
}

\author{
Gary Charness and Matthew Ellman
}

September 6, 2015

\begin{abstract}
This paper studies selection and procedural effects in experimental contracting when sellers choose unenforceable trade quality after a possible cost shock. Brandts, Charness, and Ellman (2016) investigate how communication affects behavior and outcomes in contracts with rigid prices versus contracts where buyers can raise price after observing the shock. An important remaining question is how behavior is affected by whether contract type is endogenous or experimenter-imposed. Different sorts of buyers may select contract types differently and sellers may respond differently when contract type is endogenous. Surprisingly, we find only modest effects. We draw lessons for experimental design.
\end{abstract}

Keywords: Contract types, selection effects, communication, experiments

JEL Classifications: C91, D03, D86

Acknowledgements: We would like to thank Jordi Brandts for helpful discussions and Christoph Engel, for making this paper happen.

- $\quad$ Gary Charness: University of California, Santa Barbara. 2127 North Hall, Santa Barbara, CA 93106-9210. charness@econ.ucsb.edu

- Matthew Ellman: Institut d'Anàlisi Econòmica (CSIC) and Barcelona GSE. Matthew.ellman@iae.csic.es Ellman acknowledges the Spanish Ministry of Economics and Competitiveness (Grant: ECO2014-59959) and the Generalitat de Catalunya (Grant: SGR 2014-2017). 


\section{Introduction}

Sellers of services and many goods have substantial discretion over quality after agreeing to trade because formal contracts cannot specify all details of the service to be performed. In such environments, the parties' perceptions of the agreement and relevant norms determine whether and how they respond to their necessarily-informal agreements. As MacLeod (2007) points out, a key factor underpinning successful trading relationships is the extent to which there is a "mutual understanding of the events that determine contract breach".

Brandts, Charness, and Ellman (forthcoming) - hereafter BCE - found that communication plays a vital role in terms of contract selection, quality, and mutually-beneficial outcomes. A primary feature of that study is the choice between two types of contract: flexible and rigid. With flexible contracts, the buyer sets an initial price, which could be increased after the parties observe whether the seller suffers a cost shock; with rigid contracts, the initial price is automatically also the final price. The process: the buyer chooses a contract form and a price; the seller can accept this proposal or reject it; in the latter case, the parties receive outside options. Upon acceptance, all parties observe any cost shock. The final price is then determined and made known, and the seller then chooses an unenforceable level of quality. If there is free-form communication (chat), discussions can start before the contract is chosen and can continue after parties observe the cost shock and any subsequent price change.

The focus of this article is to consider how behavior and outcomes differ according to whether the buyer chooses between the flexible and rigid contract options or whether the experimenter imposes the contract form, capturing the case of exogenous determination. Both contract-determination procedures are found in the field: in some environments, traders choose their contract type, in others the contract type is fixed, perhaps by hierarchy or standard practice. 
$\mathrm{BCE}$ and related works have focused on the endogenous setting. This is reasonable given the many field environments where traders do have a choice. ${ }^{1}$ Nevertheless, a clean test of the relative performance of flexible and rigid contracts requires exogenous contracts, as it is entirely possible that different types of buyer choose different contract forms, coloring the results. It is also possible that buyers react to the procedure of contract determination per se or that sellers respond differently to chosen than to assigned contract forms.

Flexible contracts have the obvious advantage of allowing traders to adapt their actions to new circumstances: the buyer can adapt the final price to share the burden of the cost shock faced by the seller, and this voluntary sharing makes the seller more likely to cooperate. However, flexibility leaves room for ongoing disagreement over appropriate actions. The risk of such costly disagreements led Hart and Moore (2008) to posit that quality may well be lower with flexible contracts. ${ }^{2}$ Indeed, without communication, there is rather modest support for this prediction. By contrast, when the parties are able to engage in free-form communication, flexible contracts lead to much better outcomes than do rigid ones since communication enables them to establish an effective rapport and helps them to reach a mutual understanding on actions to be taken with and without the seller cost shock.

A major contribution of this article is to consider the claim made in BCE that there is little difference in price, quality, and profits across endogenous and exogenous contracts. We compare rigid and flexible contracts from each endogenous-contract treatment with the corresponding rigid and flexible contracts from (two) exogenous-contract treatments. We do this for the environments both with and without chat, that is, we compare the two endogenous

\footnotetext{
${ }^{1}$ It can also lower experimental costs since it typically reduces the number of sessions that need to be run.

${ }^{2}$ For a more in-depth discussion of the issues relating to rigid and flexible contracts in the light of the theory in Hart and Moore (2008), interested readers should consult BCE and references therein.
} 
treatments against the four exogenous treatments. The results of the comparisons, both in the chat and no-communication settings, indicate limited selection and procedural effects: buyers' other actions and sellers' responses are, with few exceptions, essentially the same, for each contract type whether that type was assigned or chosen.

A second, perhaps greater, contribution is the attempt to evaluate when and how an experiment can be designed to reduce the need for running exogenously-imposed choices to deal with selection and procedural effects. Policy-makers and economists are often interested in how a specific option (such as our contract type) affects the interaction between a set of actors. This specific option may be imposed exogenously (by actors outside this interacting set) or determined endogenously by the actors or some subset of them; in our endogenous designs, the buyers choose the contract type (with sellers perhaps using voice to influence their choices in the chat treatments). Given the much greater costs of having to run exogenous treatments even for field environments where the option is generally chosen endogenously, it is important to know whether this added expense is really needed.

The general problem is as follows. First, the alternative options, say there are two of them as with rigid and flexible, generate outcome variations independent of the procedureendogenous or exogenous - that determined which option arises. We call this the "instrumental variation" since it depends on the direct consequences of each option for an average individual; for instance, flexibility is an instrument for adaptation with ambiguity as a possible sideconsequence. The difference between these instrumental effects is the key unknown of interest for field settings where the action is set exogenously, perhaps by a regulator or a hierarchical superior of the interacting set of parties, or effectively exogenous, as when the parties could choose the option but most of them simply follow a norm without thinking. 
Second, endogenous determination of the options can matter to the actors per se and can moderate how each option affects outcomes. These are valid effects of interest for field settings in which the options are endogenous. Process-dependent preferences and framing effects can directly affect actors' behaviors. For instance, endogeneity may lead the choosing actors to feel, and responding actors to deem them, more responsible. We will argue that the relevance of this much-studied effect depends on whether the option discretion represents a substantial amount of the choosers' overall discretion. We call these direct procedural effects. Other examples include (action-based) reciprocity, but note that reciprocity can arise indirectly via signaling and inference about the chooser's characteristics (or "type"). We call this latter case an instance of strategic procedural effects: endogenous choice reveals information to others, precisely because of the third effect.

Third, selection effects arise when actors of different types choose both the option and other actions differently. An important source of actor heterogeneity is in social preferences and this can distort apparent consequences of the choice of a given option, since social preferences are fairly stable. For instance, if (and we will argue that designs can reduce this likelihood) generous types of buyer tend to pick flexible contracts than flexible contracts will be associated with another consequence of generosity: high transfers. Such selection effects can be vital to understand field data with endogeneity, but the policy or strategy question requires controlling for selection effects, given that changing a policy design or strategy does not change the type of the actors involved.

We care about the relative size of these three types of effect. When the option of interest is a minor factor in the overall level of discretion of the relevant actors, and other direct procedural effects appear unimportant, it may be possible to design endogenous experimental 
studies so as to limit the strength of selection effects (and corresponding strategic procedural effects).

The remainder of this article proceeds as follows. Section 2 offers a brief literature review and section 3 describes the experimental design and implementation. The experimental results are presented in section 4 , and section 5 provides some discussion and concludes.

\section{Related literature}

Given that the emphasis in Hart and Moore (2008) is on the relative performance of rigid contracts versus flexible contracts, it is rather surprising that there is so little research that conducts tests with contract forms that have been assigned rather than chosen. Instead, the experimental literature on this topic has primarily considered endogenous contracts. This could be problematic to the extent that selection and signaling effects may well be present. Different types of people (here, buyers) may choose differently, and the choice of contract form may well reveal information (here, about buyers) that affects responses (here, by sellers).

The first article in this area is Fehr, Hart and Zehnder (2009) - hereafter FHZ - which provides some evidence that flexibility can have negative consequences that may be attributed to ongoing disagreements. In a context with (asymmetric) competition and ex-ante uncertainty over a potential shock to the seller's cost, they find that buyers are better off choosing rigid contracts than by choosing flexible contracts. ${ }^{3}$ Rigid contracts generate a higher average profit

\footnotetext{
${ }^{3}$ As summarized in BCE: Two potential buyers are matched with two potential sellers. Each seller has two units to sell and each buyer has a one-unit demand. Each buyer determines a contract type (rigid or flexible) and the two sellers compete over price (an exogenous price interval prevents loss-making trades). Then the seller cost shock is determined. If the contract is flexible, the buyer can respond by unilaterally increasing the price to be paid (subject to the no-loss upper bound). After learning the final price, the seller trades exactly when the price covers cost (this seller behavior is actually imposed rather than "at will"). If trading, the seller chooses between normal and low quality. Choosing low is costly to the seller, but much more costly to the buyer.
} 
for buyers, but seller profits are lower, resulting in little difference for total earnings. Buyers choose rigid contracts 50 percent of the time.

$\mathrm{BCE}$ avoids two less realistic features of FHZ. First, FHZ only permit the seller to adjust quality downwards, excluding costly efforts that raise quality. This exclusion is likely to favor rigid contracts because rigid contracts would otherwise suffer, relative to flexible ones, from the fact that they prevent buyers from using unexpected price increases to motivate costly effort. Second, FHZ do not allow trade after a cost shock though sellers may well wish to trade even at a loss if they deem the contract to be fair on average. FHZ use this imposed no-trade choice (and a parallel imposed-trade choice) as a short-cut for studying the "at will" contracting environment where both parties can always opt out of trade. BCE avoid this problem by studying the simpler case of specific-performance contracting.

We also highlight another design simplification introduced by BCE - removal of the asymmetric competition stage of FHZ. This proves most valuable for minimizing selection and strategic procedural effects that otherwise complicate an understanding of the basic rigid-flexible tradeoff.

Our contribution here is to exploit the fact that BCE considered exogenously-determined contract types in addition to the endogenous case. This feature permits both a clean test of the relative effectiveness of the two contract forms and a measure of the role played by selection and procedural effects in generating the results under endogenous contract type.

To the best of our knowledge, the only other research on endogenous versus exogenous contract forms is Erlei and Reinhold (2012). They note that sellers in FHZ have reason to blame buyers for selecting rigid contracts, since under rigidity, seller competition drives total price down to a minimum. They replicate FHZ's endogenous contracts, finding more low quality than 
in FHZ, especially for rigid contracts, and buyers choose flexible contracts 72.3 percent of the time; buyer payoffs are higher for rigid but this difference is no longer significant. They also conduct a new treatment in which contract types are exogenously determined by the experimenter. While some might argue that this change in experimental design should not have an impact on behavior, they find that the new design results in a substantial change in behavior. The significant differences in subjects' behavior in replicating sessions compared to that observed in the original study of FHZ indicates some robustness concerns, but the difference between the exogenous and endogenous design variants might suggest that exogenous treatments are vital. Fortunately, our results here show that in our simpler design, the endogeneityexogeneity differences become very limited. ${ }^{4}$

We attribute our more optimistic results to the design simplifications mentioned above and our removal of the asymmetric-competition feature. Since our study has no seller competition obliging rigid contracts to be ungenerous (low price) as well as rigid (fixed price). That is, by removing the asymmetric competition of FHZ, we avoid tying up price rigidity and low prices. ${ }^{5}$ Isolating rigidity from the choice of price level separates rigidity and generosity so that picking rigid is no longer automatically ungenerous. In this symmetric setting, we have no automatic reason to expect selection and strategic procedural effects, such as signaling. Of course, in principle, subtler selection effects may still be present. Our results reassuringly indicate that with suitable symmetry, endogenous designs are likely to be reliable.

There is considerable evidence that choosing an action rather than having this action mandated affects the chooser's behavior and the responses of others to the action. In the field,

\footnotetext{
${ }^{4}$ Note that our design avoids mixing in a strategic effect of exogeneity, since there is no competitive process to oblige low transfers in the rigid contract.

${ }^{5}$ In most field settings, fixed prices are not necessarily low prices; indeed, higher prices may often accompany rigid contracts as a way to compensate for the fact that they imply a lack of insurance.
} 
Levine and Tyson (1990), Bonin, Jones, and Putterman (1993), and Black and Lynch (2001) all show that worker participation (such as voice) in workplace decisions may positively affect productivity. ${ }^{6}$ Similarly, Bardhan (2000) finds that farmers are less likely to violate irrigation rules when they have chosen the rules. Tyran and Feld (2006) and Ertan, Page, and Putterman (2010) provide experimental evidence that punishment and rewards have a stronger effect on behavior when the possibility of making these choices has been chosen democratically. And yet, a major problem regarding the interpretation of the results in these papers is that one cannot rule out the possibility that when individuals or groups get to make more choices, different options in the sample are associated with different distributions of preferences than individuals or groups to whom a policy ("choice") has been assigned and may affect the observed consequences of those choices.

There are several experimental studies that address the problem of selection. Dal Bó, Foster, and Putterman (2010) use a procedure that determines whether payoffs in a Prisoner's Dilemma are modified to create a coordination game. Participants first vote on whether to modify the payoffs. A computer then chooses (randomly) whether these votes count: if they do, then the majority rules; if they do not, the computer chooses (again randomly) whether or not to modify the payoffs for that group. The payoff modification impacts behavior more when it is chosen than when it is imposed. The authors do find evidence of a selection effect, in that people voting to modify payoffs differ from those who voted against modification. This design offers a

\footnotetext{
${ }^{6}$ Voice (expressing one's views) can play a part in one's feelings about an outcome. For example, Kitzmann and Emery (1993) find a much higher degree of satisfaction by fathers (with random assignment) in child-custody disputes when they participated in the process, even though they (almost) always lost. Ellman and PezanisChristou (2010) show that members of an organization feel more (morally) responsible for a harm caused by their organization when they had a more active role as participants in choosing the group action that initiated that harm. This identifies a direct procedural effect since the level of participation is exogenous.
} 
neat solution for distinguishing categorical selection effects, but it does introduce a degree of complexity that may be problematic for subjects' understanding.

Sutter, Haigner, and Kocher (2010) vary whether a computer exogenously chooses the institution of punishment or reward in a public-goods game or the group itself chooses it through a voting procedure. In the endogenous treatments, participants could determine the institution prevailing in their group by each voter indicating whether he or she was willing to accept this institution or not. The vote was repeated until unanimity was achieved. The results indicate that there is a positive direct procedural effect from a voluntary choice of a reward or punishment mechanism on the level of cooperation within groups, independent of which option is chosen.

Corgnet, McCarter, and Hernan (2014) assign people to a setting in which the internet is turned off in the first part of the experiment, while people vote on whether to do so in the second part. All but one group voted to turn off the internet, with production (at least for the subjects who used the Internet in the first half of the experiment) larger with voting. Herbst, Konrad, and Morath (2014) compare behavior of individuals who self-select into teams to behavior in exogenously-formed teams. They find that team choice leads to higher efforts than exogenous team assignment, even though, in their experiment, selection works against this effect in that types who provide high effort prefer to stand alone.

Babcock, Bedard, Charness, Hartman, and Royer (2015) provide the cleanest result regarding choice, as there is virtually no selection effect possible since almost all subjects made the same choice (only 3 percent chose the team treatment). They compared people who were assigned to an individual treatment and people who chose the individual treatment, finding that those people who made this choice registered a performance that was 27 percent higher than for 
the assigned individual group. This difference cannot be explained by selection since only three percent of the subjects chose an alternative team treatment rather than the individual one. ${ }^{7}$

In view of the numerous studies showing that endogenous choice leads to greater cooperation and pro-social behavior, the expectation was that there would be less favorable results with exogenous imposition of the contract form. ${ }^{8}$ However, we shall see that this is not the case in BCE's setting. We interpret these results in two ways. First, they suggest that when a choice of interest (here, the flexibility of contract form) is not intrinsically tied to a distributive position, then the design should seek to avoid features (such as asymmetric competitive positions) that interact with the focal choice to force distinct distributive implications. This strategy limits the risk of selection effects. It similarly limits strategic procedural effects based on signaling and inference. Second, direct procedural effects of the act of choosing do not seem important in our context, because the buyer still has a significant amount of discretion in the exogenous treatments.

\section{Experimental design and implementation}

Here we borrow from BCE to describe the relevant treatments. Participants play the same one-shot game in each of 10 periods (plus one practice period). Across periods, they are re-matched and no two individuals ever play each other twice or observe another's behavior in past periods (nor any average outcomes), so there is no way to build a personal reputation. Since the same game is played independently in each period, we can focus our analysis on the basic

\footnotetext{
${ }^{7}$ This result stems from a required revision that initially seemed rather silly because one option was clearly dominated. There were two possible options: a team option in which both team members needed to reach a threshold for a reward to be generated, and an individual option that required this threshold for just that one individual (for the same reward).

${ }^{8}$ Of course, studies finding no difference may have been subject to the publication bias, and so are unobserved.
} 
game, bearing in mind that subjects may learn how to play over time. ${ }^{9}$

There were two treatments with endogenous choice of contract form, so that the buyer could choose to offer a rigid or flexible contract (with four sessions in each). These consist of a no-communication treatment and a chat treatment. There were also four treatments (four sessions in each) with endogenous contract types (no communication and rigid contracts, no communication and flexible contracts, chat and rigid contracts, and chat and flexible contracts), These exogenous contract treatments serve to control for the possibility that selection or direct endogeneity effects drive results and here we focus on the comparison between the endogenous and exogenous results.

\subsection{Details and parameters of the basic game}

Sample instructions are presented in Appendix A. The buyer can choose a contract type and a price $\mathrm{P}$. The seller then accepts or rejects the offer. If no contract is accepted, the buyer and seller each receive outside option payments. If the seller accepts a contract offer, the seller provides a good to the buyer. The seller's cost is subject to a shock, C, which both buyer and seller observe. If a flexible contract was chosen, the buyer can augment the initial price P by any amount, which we denote by Q. However, if a rigid contract was chosen at the initial stage, the initial price cannot be changed. After observing Q, the seller chooses the good's quality, $x$. Formally, buyer and seller respectively earn monetary payoffs of $5+\mathrm{v}(x)-\mathrm{P}-\mathrm{Q}$ and $5+\mathrm{P}+\mathrm{Q}$ $-\mathrm{C}-|x|$ if they trade and 5 each if not, where the buyer's trade value $\mathrm{v}(x)=10,30$, or 45 , for $x$ $=-1,0,+1$, and $\mathrm{C}$ is either 0 or 20 , with equal probability.

\footnotetext{
${ }^{9}$ As argued in BCE, the lack of repetition makes the analysis more relevant to one-shot interactions, such as when the buyer is a final consumer, rather than an employer or outsourcer, but as argued in MacLeod (2007), the behavioral enforcement of informal agreements that applies in one-shot interactions has strong parallels with repeated-game enforcement, so the results should have a broader relevance.
} 


\subsection{Timing}

The sequence of events for the treatments with exogenous contract is defined by the following five-stage game in which both parties observe the outcomes of all preceding stages:

Stage 1: Buyer B sets the contract's initial price offer $P$.

Stage 2: Seller $S$ accepts or rejects this offer.

Stage 3: The computer randomly determines the seller's base cost $C$ at 0 or 20.

Stage 4: If the contract is flexible, buyer B sets an additional transfer $Q$.

Stage 5: Seller $S$ sets the quality level, $x=-1, x=0$ or $x=1$.

The sequence is the same with endogenous contracts, except that the buyer also chooses whether the (stage 1) offered contract is rigid or flexible.

In the chat treatment, the buyer and seller can additionally engage in free-form communication, sending each other written messages, starting from the moment they are matched right up until the seller sets quality $x$ in the final stage (stage 5).

\subsection{Implementation}

Sessions were conducted at the LINEEX laboratory (Valencia, Spain). Each session had groups of 22 people who played 10 periods (and a practice period); no one participated in more than one session. To eliminate income effects, one period was randomly selected for payment at the end of each session. Each payoff unit was worth $1 €$, and participants received an $8 €$ show-up fee. In the six treatments, we ran 24 sessions with 528 participants, with average earnings of about $17 €$ for no-communication sessions, and $25 €$ for chat sessions, which were respectively about 90 and 120 minutes in duration.

Participant roles (buyer or seller) were fixed for the duration of their session and it was common information that no participants were ever matched together twice. Instructions and a careful explanation were read aloud at the start of each session. An always-available help screen enabled each participant to (privately) compute own and current partner payoffs from any set of 
feasible choices he or she wishes to consider.

\section{Experimental results}

In this section, we first provide descriptive statistics and then non-parametric tests on the outcomes observed in our six treatments. We close with regression analysis of the differences across the relevant pairs of exogenous and endogenous contracts. The main effects can be observed directly by looking at the treatment level data presented in Tables 1 and 2 . We refer the reader to $\mathrm{BCE}$ for a thorough analysis of the main conjectures in $\mathrm{BCE}$ and in particular the fact that all BCE's principal results hold for both exogenous and endogenous variants. A brief summary of those results is as follows:

$>$ Chat increases earnings and quality, especially for flexible contracts.

$>$ Chat sharply increases cost-sharing $(\mathrm{Q})$ for flexible contracts.

$>$ Chat leads to a substantial advantage of flexible over rigid contracts.

$>$ Chat leads to a switch from rigid (slightly more frequent without communication) to flexible contracts (far more frequent with chat).

\subsection{Descriptive statistics}

Table 1 describes the contracts chosen, prices and transfers, rejections, quality levels, and earnings for the no-communication treatments, with endogenous and exogenous conditions in adjacent columns. Table 2 presents the same information for the communication treatments.

Visual inspection shows few substantial differences across endogenous and exogenous conditions, so by and large the results with respect to quality and earnings are mainly the same. The only sizable difference for rigid contracts without communication is in the seller earnings, which are two-to-three units higher for exogenous contracts. For flexible contracts without communication, exogenous contracts have a slightly lower rejection rate, a somewhat higher quality level, and seller earnings are once again two-to-three points higher. The only real 
difference for rigid contracts with chat across endogeneity is the slightly lower rejection rate for exogenous contracts. For flexible contracts with chat and exogenous contracts, there is a little more cost-sharing (the increase in Q across cost-shock conditions), a slightly lower quality level, and seller earnings are about two points lower.

Table 1: Summary Statistics: No-communication Treatments

\begin{tabular}{|l|c|c|c|c|}
\hline Category & $\begin{array}{c}\text { Endo Rigid } \\
\text { No Comm. }\end{array}$ & $\begin{array}{c}\text { Exo Rigid } \\
\text { No Comm. }\end{array}$ & $\begin{array}{c}\text { Endo Flex } \\
\text { No Comm. }\end{array}$ & $\begin{array}{c}\text { Exo Flex } \\
\text { No Comm. }\end{array}$ \\
\hline Frequency* & $243(55.4 \%)$ & $436(100.0 \%)$ & $196(44.6 \%)$ & $438(100.0 \%)$ \\
\hline Rejections & $79(32.5 \%)$ & $152(34.9 \%)$ & $65(33.2 \%)$ & $119(27.2 \%)$ \\
\hline Average P (all offers) & $13.28[0.41]$ & $13.91[0.31]$ & $11.59[0.59]$ & $12.44[0.28]$ \\
\hline Average P (accepted offers) & $15.74[0.43]$ & $16.28[0.33]$ & $13.25[0.81]$ & $14.21[0.31]$ \\
\hline Average Q (with cost shock) & - & - & $3.35[0.49]$ & $4.18[0.67]$ \\
\hline Average Q (with no cost shock) & - & - & $3.41[1.85]$ & $3.21[0.37]$ \\
\hline Low quality (accepted offers) & $51(31.1 \%)$ & $86(30.3 \%)$ & $53(40.5 \%)$ & $108(33.9 \%)$ \\
\hline Normal quality (accepted offers) & $107(65.2 \%)$ & $183(64.4 \%)$ & $74(56.5 \%)$ & $174(54.5 \%)$ \\
\hline High quality (accepted offers) & $6(3.7 \%)$ & $15(5.3 \%)$ & $4(3.1 \%)$ & $37(11.6 \%)$ \\
\hline Avg. quality (accepted offers) & $-0.27[0.04]$ & $-0.25[0.03]$ & $-0.37[0.05]$ & $-0.22[0.04]$ \\
\hline Avg. buyer earnings (all offers) & $10.80[0.60]$ & $10.51[0.47]$ & $8.84[1.09]$ & $10.16[0.48]$ \\
\hline Avg. buyer earnings (accepted offers) & $13.59[0.77]$ & $13.45[0.65]$ & $10.74[1.61]$ & $12.08[0.62]$ \\
\hline Avg. seller earnings (all offers) & $7.81[0.59]$ & $9.96[0.48]$ & $7.96[1.22]$ & $10.62[0.57]$ \\
\hline Avg. seller earnings (accepted offers) & $9.17[0.86]$ & $12.62[0.68]$ & $9.44[1.81]$ & $12.71[0.75]$ \\
\hline Avg. total earnings (all offers) & $18.61[0.88]$ & $20.47[0.69]$ & $16.80[0.99]$ & $20.78[0.79]$ \\
\hline Avg. total earnings (accepted offers) & $22.76[1.18]$ & $26.07[0.90]$ & $20.18[1.40]$ & $24.80[0.99]$ \\
\hline
\end{tabular}

No contract was offered on some occasions. P refers to the initial (pre-cost-shock) price, while Q refers to the transfer added with flexible contracts after the cost shock. Standard errors are in brackets. 
Table 2: Summary Statistics: Chat Treatments

\begin{tabular}{|l|c|c|c|c|}
\hline Category & $\begin{array}{c}\text { Endo Rigid } \\
\text { Comm. }\end{array}$ & $\begin{array}{c}\text { Exo Rigid } \\
\text { Comm. }\end{array}$ & $\begin{array}{c}\text { Endo Flex } \\
\text { Comm. }\end{array}$ & $\begin{array}{c}\text { Exo Flex } \\
\text { Comm. }\end{array}$ \\
\hline Frequency* & $111(25.3 \%)$ & $438(100.0 \%)$ & $327(74.5 \%)$ & $440(100.0 \%)$ \\
\hline Rejections & $20(18.0 \%)$ & $61(13.9 \%)$ & $12(3.7 \%)$ & $18(4.1 \%)$ \\
\hline Average P (all offers) & $22.76[0.83]$ & $23.04[0.46]$ & $16.92[0.46]$ & $13.14[0.31]$ \\
\hline Average P (accepted offers) & $25.22[0.72]$ & $25.38[0.41]$ & $17.22[0.47]$ & $13.47[0.30]$ \\
\hline Average Q (with cost shock) & - & - & $13.08[0.49]$ & $15.89[0.55]$ \\
\hline Average Q (with no cost shock) & - & - & $7.25[0.30]$ & $8.44[0.44]$ \\
\hline Low quality (accepted offers) & $13(14.3 \%)$ & $63(16.7 \%)$ & $20(6.3 \%)$ & $50(11.8 \%)$ \\
\hline Normal quality (accepted offers) & $33(36.3 \%)$ & $124(32.9 \%)$ & $61(19.4 \%)$ & $85(20.1 \%)$ \\
\hline High quality (accepted offers) & $45(49.5 \%)$ & $190(50.4 \%)$ & $234(74.3 \%)$ & $287(68.0 \%)$ \\
\hline Avg. quality (accepted offers) & $0.35[0.08]$ & $0.34[0.04]$ & $0.68[0.03]$ & $0.56[0.03]$ \\
\hline Avg. buyer earnings (all offers) & $12.66[0.99]$ & $12.61[0.54]$ & $17.02[0.56]$ & $16.58[0.49]$ \\
\hline Avg. buyer earnings (accepted offers) & $14.34[1.14]$ & $13.84[0.61]$ & $17.48[0.56]$ & $17.07[0.50]$ \\
\hline Avg. seller earnings (all offers) & $16.68[1.16]$ & $17.50[0.62]$ & $20.95[0.46]$ & $19.03[0.47]$ \\
\hline Avg. seller earnings (accepted offers) & $19.25[1.27]$ & $19.52[0.67]$ & $21.56[0.44]$ & $19.63[0.47]$ \\
\hline Avg. total earnings (all offers) & $29.34[1.72]$ & $30.11[0.84]$ & $37.97[0.84]$ & $35.61[0.78]$ \\
\hline Avg. total earnings (accepted offers) & $33.59[1.81]$ & $33.36[0.86]$ & $39.03[0.81]$ & $36.70[0.77]$ \\
\hline
\end{tabular}

No contract was offered on some occasions. In the column for endogenous flexible contracts with chat, one case is exclude (when calculating prices, quality, and earnings) in which the buyer received an extremely large negative payoff. P refers to the initial (pre-cost-shock) price, while Q refers to the transfer added with flexible contracts after the cost shock. Standard errors are in brackets.

\subsection{Non-parametric tests}

A conservative testing philosophy treats each session as just one observation, so that there are only four observations for each treatment; the data for each session is presented in 
Appendix B. ${ }^{10}$

\section{Earnings}

Considering first the no-communication treatment with rigid contracts and earnings over all offers, two-tailed Wilcoxon-Mann-Whitney tests show no significant differences for endogenous and exogenous rigid contracts $(p=0.886$ for buyer earnings, 0.343 for seller earnings, and 0.486 for total earnings). With no communication and flexible contracts, these tests find a significant difference only for seller earnings ( $p=0.486$ for buyer earnings, 0.057 for seller earnings, and 0.200 for total earnings); this difference reflects lower earnings from the endogenous treatment for sellers with flexible contracts.

For the chat treatment, two-tailed Wilcoxon tests show no difference at all across endogenous and exogenous rigid contracts (again, $p=0.886$ for buyer earnings, 0.886 for seller earnings, and 0.686 for total earnings). The same test across flexible contracts finds a significant difference only for seller earnings $(p=0.886$ for buyer earnings, 0.057 for seller earnings, and 0.486 for total earnings) and a modest one for total earnings, both differences in favor of higher earnings with endogenous flexible contracts. That is, the impact of selection effects appears to be limited to seller earnings with flexible contracts. Endogeneity appears to have negative selection effects in the no-communication case and positive effects in the chat environment.

\section{Quality}

Results on tests for quality differences are broadly similar to those for earnings, and even more encouraging, since there are no significant differences between exogenous and endogenous designs, as we now detail. In the treatments with no communication and rigid contracts, two-

\footnotetext{
${ }^{10} \mathrm{We}$ forego the more powerful but less pure statistical approach of using individual-level data. It is less pure because subjects within sessions interact and can influence each other over multiple periods, so that individual trading pair outcomes are definitely not independent of other pairs.
} 
tailed tests data find no significant difference in quality across endogenous and exogenous accepted contracts (quality is only observed after acceptance), with $p=0.886$. Quality appears to be higher with exogenous flexible contracts given no communication but this is not significant ( $p$ $=0.200$ ). Similarly, in the chat treatments, there is no significant difference in quality across endogenous and exogenous rigid accepted contracts $(p=0.343)$, and no such quality difference for accepted flexible contracts either $(p=0.686)$.

\section{Total transfers}

The total transfer paid in (accepted) contracts is another indicator for differences between endogenous and exogenous contracts. In the no-communication scenario, there is no difference between endogenous and exogenous for either rigid or flexible contracts $(p=1.000$ and $p=$ 0.114 , respectively) but for flexible contracts, exogeneity is almost significantly associated with higher total transfers, as is consistent with the higher seller earnings. With chat, there is also no difference for rigid contracts $(p=0.886)$, but again there is a significant difference for flexible contracts $(p=0.029)$ only now in the opposite direction: higher total transfers under endogeneity.

In sum, the differences are minimal and limited to the following exceptions: total transfers and seller earnings are both higher under endogeneity in the chat treatment and the converse effect arises in the no-communication treatment, though seller earnings do not quite differ significantly there. Clearly, the total transfer rise fits well with the higher seller earnings. ${ }^{11}$ But why might buyer transfer choices vary in this way with endogeneity? We discuss this in the conclusion after first corroborating these patterns in a regression analysis.

\subsection{Regression analysis}

\footnotetext{
11 That quality, while moving in parallel with the transfer shifts, does not do so significantly, most likely reflects the low magnitude of the transfer effects.
} 
In this section, we study the effects of the treatments using simple regression analysis.

The results essentially confirm the non-parametric tests reported above. The coefficients and standard errors from pairwise regressions (clustered at the session level) across endogenous and exogenous contracts are shown in Table 3.

We regress the relevant outcome variables on a dummy for exogeneity of the contract form. The regressions show that there are few significant differences from changing the endogeneity of contract form. As in the non-parametric tests, the exceptions relate to flexible contracts so we focus on flexible contracts. Without communication, there are mildly significant differences in quality and total transfers in favor of exogenous contracts when there is no communication (and a marginally-significant difference in total earnings). By contrast, with chat this is rather different. Now total transfers and seller earnings are significantly higher with endogenous contracts.

Table 3: Comparisons across treatments, Random-effects regressions

\begin{tabular}{|c|c|c|c|c|c|}
\hline Comparison & $\begin{array}{c}(1) \\
\text { Buyer } \\
\text { Earnings }\end{array}$ & $\begin{array}{c}(2) \\
\text { Seller } \\
\text { Earnings }\end{array}$ & $\begin{array}{c}(3) \\
\text { Total } \\
\text { Earnings }\end{array}$ & $\begin{array}{c}(4) \\
\text { Quality }\end{array}$ & $\begin{array}{c}(5) \\
\text { Total } \\
\text { Transfer }\end{array}$ \\
\hline Rigid, no chat & $\begin{array}{c}-0.468 \\
(1.254)\end{array}$ & $\begin{array}{c}2.122 \\
(1.424)\end{array}$ & $\begin{array}{c}1.697 \\
(1.382)\end{array}$ & $\begin{array}{c}0.016 \\
(0.064)\end{array}$ & $\begin{array}{c}0.515 \\
(1.296)\end{array}$ \\
\hline Flex, no chat & $\begin{array}{c}0.489 \\
(1.015)\end{array}$ & $\begin{array}{c}3.665^{* * *} \\
(1.512)\end{array}$ & $\begin{array}{c}4.173^{*} \\
(2.322)\end{array}$ & $\begin{array}{c}0.150^{*} \\
(0.079)\end{array}$ & $\begin{array}{c}2.672^{* *} \\
(1.066)\end{array}$ \\
\hline Rigid, chat & $\begin{array}{c}0.306 \\
(1.485)\end{array}$ & $\begin{array}{c}1.299 \\
(2.526)\end{array}$ & $\begin{array}{c}1.544 \\
(3.223)\end{array}$ & $\begin{array}{c}0.044 \\
(0.130)\end{array}$ & $\begin{array}{c}1.020 \\
(2.204)\end{array}$ \\
\hline Flex, chat & -0.224 & $-1.878^{* * *}$ & -2.141 & $-0.115^{*}$ & $-1.638^{* * *}$ \\
$(1.321)$ & $(0.568)$ & $(1.684)$ & $(0.068)$ & $(0.380)$ \\
\hline
\end{tabular}

Entries are coefficients from GLS regressions. Standard errors are in parentheses. Earnings regressions use all contract offers, while quality is only given for trade acceptance and total transfer uses only accepted contracts. $* * *, * *$, and $*$ indicate significance at $p=0.01,0.05$, and 0.10 (two-tailed tests), respectively. One case with an extreme buyer loss and seller gain is excluded. Clustering is at the session level. Positive coefficients reflect higher values in the exogenous treatments. 


\section{Discussion \& Conclusion}

Previous literature in this area has largely ignored the issue of potential selection effects when a contract choice is endogenous. If one is interested only in the overall behavior of participants in an endogenous setting, and one believes that selection effects are small and choice of contract form per se has limited direct effects (say, because the relevant actors have substantial discretion either way), then this is not unreasonable. But for a more careful test of the performance of contracts per se, one needs to utilize contracts that have been imposed by an external entity to avoid the influence of any selection effects. The main focus of BCE is on the effect of communication on behavior with endogenous contracts. In this paper, we instead consider whether there are differences across contracts types that are chosen by a party to the contract or selected by the experimenter.

We see that by and large there are few differences across behavior with respect to the source of a particular contract type. The primary patterns in BCE survive with exogenous contracts. This is really good news for the studies that have ignored this issue, since their findings regarding the performance of contract types do not have to be discarded.

Nevertheless, there are some rather modest differences across endogenous and exogenous contracts. There is no significant difference in this respect for rigid contracts (either with or without chat), but there are some differences with flexible contracts. Specifically, without communication, sellers have higher earnings when flexible contracts are exogenously determined and this effect is reversed with chat, sellers have higher earnings in the endogenous case. Coinciding intuitively with this pattern, transfers (price paid) from buyer to seller are higher with flexible exogenous contracts without communication, but are lower with flexible endogenous contracts. 
We interpret the higher transfer and seller earnings under endogenous flexible contracts in the chat treatment via how sellers' use the chat. Sellers typically encourage buyers to pay higher transfers and to choose flexible (in order to share in their cost). We already argued against the typical channel for selection effects based on heterogeneity in distributive social preferences, but there is a subtler possibility. Buyers may be heterogenous in their responsiveness to seller pressure and sellers may differ in their persuasiveness. In chat treatments where sellers influence buyers, we can expect both higher transfers, and under endogeneity, more flexible choices. So endogenous flexible will feature higher transfers and therefore higher seller earnings than do exogenous flexible contracts.

In the case without chat, endogenous flexible may be associated with lower transfers because endogeneity makes buyers feel more powerful and more deserving, but we argued above that such direct procedural effects are not likely given the buyer always has substantial discretionary powers. Perhaps a more plausible explanation is that the type of buyer who selects flexible contracting under no-communication underestimates sellers' negative reaction to ambiguity and also to low transfers. If so, the buyers using flexible contracts in the endogenous, no-communication treatment are also the type of buyers who are likely to set transfers too low.

Notice that the BCE design does not preclude all distributional-preference-based selection and signaling effects. It is just that such effects are more complicated since they necessarily operate through attitudes to the distribution of payoff uncertainty and not just of payoff levels. Moreover, it is not easy to come up with plausible selection stories that fit the endogeneity effects in our data. For instance, buyers may differ in their concern for sharing in the seller's cost uncertainty and we might expect these sharing types of buyer to also be more generous. But this would predict higher not lower total transfers in the no-communication 
treatments for those buyers who choose flexible (in order to share), compared to those assigned flexible.

One might conceivably argue that those buyers who want to share in the nocommunication treatment are actually meaner types who only pick flexible because they believe sharing will earn them an insurance premium, or who plan to trick sellers by paying no additional transfer despite their flexible choice. These explanations might work, but are rather complicated. To build a story to the results with chat as well, it is necessary to add a twist. For instance, if, with no-communication, many buyers, even pro-social ones, do not care for the seller, then chat can moderate the selection effect and potentially fit our data.

The main point, however, is that the selection effects are limited to these two factors and relatively small in magnitude.

Regarding the apparent limited presence of direct procedural effects, it is valuable to understand why we get different results to the papers discussed above in which the act of choice seems to directly motivate subjects to behave more responsibly. Notice that those papers share a common feature: their exogenous or assignment treatments leave the subjects with no choice at all over the initiating contract, be it a background institution or a team structure or an incentive contract. Since this decision is made ex-ante, we can say that the subjects have either zero or non-trivial ex-ante discretion. By contrast, in BCE, the buyer always chooses whether to offer a contract and what price to propose, even in treatments where the contract form is exogenously assigned. So the buyer participates actively in contract formation in either case. ${ }^{12}$

BCE's design avoids placing subjects into the extreme of complete noninvolvement. This is appropriate for settings where relevant policy adjustments have only a

\footnotetext{
${ }^{12}$ Seller participation is always limited to accepting or rejecting, with the added possibility of trying to influence the buyer in the chat treatments.
} 
limited effect on an agent's degree of discretion. It matters because in such settings, subjects'

psychological or ethical perception of self-control is unlikely to be affected by whether a specific

policy option is assigned or chosen, so direct effects of endogeneity become less

probable. However, an experimental design that, in the aim of simplicity, abstracts from all

other areas of agent discretion may fail to represent this situation, artificially turning the

assignment treatment into an extreme of zero ex-ante discretion.

The issue of endogenous choice has important ramifications for contracts and the design

of effective institutions. As there has really been very little work in this area, it will take a

number of further studies before empirical regularities can be established.

\section{References}

Babcock, Philip, Kelly Bedard, Gary Charness, John Hartman, and Heather Royer (forthcoming), "Letting Down the Team? Social Effects of Team Incentives," Journal of the European Economic Association.

Brandts, Jordi, Gary Charness, and Matthew Ellman (forthcoming), "Let's Talk: How Communication Affects Contract Design," Journal of the European Economic Association.

Corgnet, Brice, Matthew McCarter, and Roberto Hernan (2014). "The Effect of Participative and Autocratic Leadership in Workgroup Social Dilemmas: An Examination of Cyberloafing in a Virtual Organization," forthcoming in Management Science.

Dal Bó, Pedro, Andrew Foster, and Louis Putterman (2010),"Institutions and Behavior: Experimental Evidence on the Effects of Democracy." American Economic Review, 100(5): 2205-29.

Ellman, Matthew and Paul Pezanis-Christou (2010), "Organizational Structure, Communication and Group Ethics,” American Economic Review, 100, 2478-2491.

Herbst, Luisa, Kai Konrad and Florian Morath (2015), "Endogenous Group Formation in Experimental Contests," European Economic Review, 74, 163-189.

Erlei, Matthias and Christian Reinhold (2012), "To Choose or Not to Choose: Contracts, Reference Points, Reciprocity, and Signaling," working paper.

Fehr, Ernst, Oliver Hart and Christian Zehnder (2009), "Contracts, Reference Points, and Competition Behavioral Effects of the Fundamental Transformation," Journal of the European Economic Association, 7, 561-572.

Hart, Oliver and John Moore (2008), “Contracts as Reference Points," Quarterly Journal of Economics, $123,1-48$.

Kitzmann, Katherine, \& Robert Emery (1993). Procedural justice theory and parent satisfaction with mediated and litigated child custody disputes. Law and Human Behavior, 5, 553-566.

MacLeod, W. Bentley (2007), "Reputations, Relationships, and Contract Enforcement," Journal of Economic Literature, 45, 595-628.

Matthias Sutter, Stefan Haigner, Martin Kocher (2010), "Choosing the carrot or the stick? Endogenous institutional choice in social dilemma situations," The Review of Economic Studies, 77(4), 15401566. 


\section{Online Appendix A: Instructions}

(Notes to reader: the only difference between the chat and no-communication treatments is the presence of the paragraph on communication; the exogenous-contract and restricted-communication treatments are identical but for the minor changes indicated in section 3; we relabeled quality $x$ as response $\mathrm{R}$ to maintain normal language.)

Thanks for coming to the experiment. You will receive 8 Euro for having shown up on time. In addition you will make money during the session.

The participants have been randomly divided into two roles - agents A and agents B according to the seat number. These roles will remain constant during the whole experiment.

The experiment will have 11 periods. In each period you will be matched with another person in the other role. This person will change from period to period and you will never be paired twice with the same person. At no point will you know with whom you are matched.

Each period is independent and develops as follows. Agent A and agent B each has an endowment of 5 monetary units and an opportunity to interact. To interact with B, A has to propose a contract type (I or II) and a transfer, $\mathrm{P}$, and B must accept this; all this occurs before knowing whether B's cost is high (20) or low (0). After observing this cost (and if A and B agreed to interact), agent $\mathrm{A}$ can make an additional transfer, $\mathrm{Q}$, but only if the negotiated contract is of type II. If, by contrast, the negotiated contract is of type I, the transfer remains fixed at $P$. After observing the cost and agent A's final transfer ( $\mathrm{P}$ or $\mathrm{P}+\mathrm{Q})$, agent $\mathrm{B}$ chooses his/her response $\mathrm{R}$ between the values $-1,0$ and 1 , where $\mathrm{R}=-1$ or $\mathrm{R}=1$ imply an additional cost of 1 on $B$ relative to $R=0$. This response affects what agent $A$ receives as explained below. In fuller detail, each period contains 5 stages:

- Stage 1: Agent A proposes to agent B:

a contract of type I with a non-negative transfer $\mathrm{P}(\mathrm{I})$ --or--

a contract of type II with a non-negative transfer of P(II) (the initial transfer)

- Stage 2: Agent B accepts or rejects this proposal.

If agent $B$ rejects, then the period ends without the following steps.

If agent $B$ accepts, then the period proceeds to step 3 .

- Stage 3: The cost of agent B is randomly determined by the computer. With probability $1 / 2$ the cost is 0 and with probability $1 / 2$ the cost is 20 .

- Stage 4: If a contract of type II is agreed, then agent A can now increase the initial transfer with an additional non-negative transfer $\mathrm{Q}$ (that is, can make a total transfer of $\mathrm{P}+\mathrm{Q}$ instead of $\mathrm{P}$ ).

- $\quad$ Stage 5: Agent $\mathrm{B}$ chooses a response level $\mathrm{R}=-1, \mathrm{R}=0$ or $\mathrm{R}=1$. 
At each stage, agent A and agent B are both directly informed of what happened in all earlier stages (of that period).

At the end of a period, the results are as follows:

If agent $B$ rejects the contract proposed by agent $A$ :

Agent $\mathrm{A}$ and agent $\mathrm{B}$ each receive their initial endowment of 5 units.

If agent $B$ accepts:

Agent A receives: $15+0$ (if $\mathrm{R}=-1)+20$ (if $\mathrm{R}=0)+35$ (if $\mathrm{R}=1$ ) - transfer from $\mathrm{A}$ to $\mathrm{B}$.

Agent $B$ receives $5-\operatorname{cost}-|R|+$ transfer from $A$ to $B$.

where the cost is $=0$ or 20 , depending on the outcome given by the computer, and the transfer from $\mathrm{A}$ to $\mathrm{B}=\mathrm{P}(\mathrm{I})$ if the contract is of type $\mathrm{I}$, and

$$
=\mathrm{P}(\mathrm{II})+\mathrm{Q} \text { if the contract if of type II. }
$$

After this we will proceed to the next period which will develop in the same way. Remember that you will never play the same person twice.

The first period, called period 0 , will be a trial period and will not be taken into account in determining what you will earn in the experiment. Periods 1 to 10 will not be trial periods. One of these will be randomly selected to determine what you earn in the experiment.

Each monetary unit is worth 1 Euro. At the end of the session you will be paid 8 Euros plus what you will have earned in the period that is selected randomly.

Communication: During each period, the agents A and B, can communicate through a chat. To do this, they have to write a message in the appropriate field and push "ENTER". Each participant $\mathrm{A}$ and $\mathrm{B}$ can close his/her chat window and can open it again after having closed it (all previous messages of the period will remain visible). While one participant has his chat window closed, he/she will not be able to read or send messages, but the participant he is matched with will continue to be able to send messages (which will be visible for the matched person once he/she reopens the chat window).

It is important not to use the chat window to send messages that reveal your identity.

You can ask questions at any time. If you have a question, raise your hand and one of us will come to your cubicle to answer it.

Now we will briefly explain the screens that you will see once the experiment starts. 


\section{Online Appendix B: Session-level data}

Table B1: Behavior in session 1 of the endogenous no-communication treat

\begin{tabular}{|c|c|c|}
\hline Category & Rigid contract & Flexible contract \\
\hline Frequency* & $53(49.5 \%)$ & $56(50.5 \%)$ \\
\hline Rejections & $12(25.9 \%)$ & $11(20.0 \%)$ \\
\hline Average P & $15.15[1.07]$ & $13.00[0.83]$ \\
\hline Average Q & - & $2.44[0.58]$ \\
\hline Low quality & $10(22.5 \%)$ & $12(27.9 \%)$ \\
\hline Normal quality & $25(65.0 \%)$ & $30(9.8 \%)$ \\
\hline High quality & $5(12.5 \%)$ & $1(2.3 \%)$ \\
\hline Avg. quality & $-0.10(0.09)$ & $-0.26(0.09)$ \\
\hline Avg. buyer earnings (all offers) & $12.08[1.41]$ & $11.00[1.20]$ \\
\hline Avg. seller earnings (all offers) & $9.62[1.48]$ & $10.56[1.68]$ \\
\hline Avg. total earnings (all offers) & $21.70[1.83]$ & $20.21[1.82]$ \\
\hline
\end{tabular}

* No contract was offered on one occasion. Standard errors are in brackets.

Table B2: Behavior in session 2 of the endogenous no-communication treat

\begin{tabular}{|c|c|c|}
\hline Category & Rigid contract & Flexible contract \\
\hline Frequency* & $66(60.0 \%)$ & $44(40.0 \%)$ \\
\hline Rejections & $24(36.3 \%)$ & $23(52.3 \%)$ \\
\hline Average P & $14.18[0.61]$ & $10.00[0.55]$ \\
\hline Average Q & - & $1.78[0.83]$ \\
\hline Low quality & $14(33.3 \%)$ & $8(38.1 \%)$ \\
\hline Normal quality & $27(64.3 \%)$ & $13(61.9 \%)$ \\
\hline High quality & $1(2.4 \%)$ & $0(0.0 \%)$ \\
\hline Avg. quality & $-0.31(0.08)$ & $-0.44(0.12)$ \\
\hline Avg. buyer earnings (all offers) & $9.86[1.07]$ & $8.55[1.32]$ \\
\hline Avg. seller earnings (all offers) & $8.92[1.12]$ & $4.00[0.92]$ \\
\hline Avg. total earnings (all offers) & $18.79[1.74]$ & $12.55[1.45]$ \\
\hline
\end{tabular}

Standard errors are in brackets. 
Table B3: Behavior in session 3 of the endogenous no-communication treatr

\begin{tabular}{|c|c|c|}
\hline Category & Rigid contract & Flexible contract \\
\hline Frequency & $46(41.8 \%)$ & $64(58.2 \%)$ \\
\hline Rejections & $11(23.9 \%)$ & $15(23.4 \%)$ \\
\hline Average P & $12.93[0.88]$ & $10.66[0.48]$ \\
\hline Average Q & - & $2.78[0.44]$ \\
\hline Low quality & $9(25.7 \%)$ & $22(44.9 \%)$ \\
\hline Normal quality & $26(74.3 \%)$ & $26(53.1 \%)$ \\
\hline High quality & $0(0.0 \%)$ & $1(2.0 \%)$ \\
\hline Avg. quality & $-0.26[0.07]$ & $-0.43[0.08]$ \\
\hline Avg. buyer earnings (all offers) & $12.61[1.35]$ & $10.34[1.19]$ \\
\hline Avg. seller earnings (all offers) & $7.41[1.32]$ & $6.88[1.20]$ \\
\hline Avg. total earnings (all offers) & $20.02[2.13]$ & $17.22[1.86]$ \\
\hline
\end{tabular}

Standard errors are in brackets.

Table B4: Behavior in session 4 of the endogenous no-communication treatr

\begin{tabular}{|c|c|c|}
\hline Category & Rigid contract & Flexible contract \\
\hline Frequency & $78(71.6 \%)$ & $32(28.4 \%)$ \\
\hline Rejections & $31(39.7 \%)$ & $11(35.5 \%)$ \\
\hline Average P & $11.45[0.76]$ & $10.35[1.19]$ \\
\hline Average Q & - & $3.45[0.72]$ \\
\hline Low quality & $18(38.3 \%)$ & $11(55.0 \%)$ \\
\hline Normal quality & $29(61.7 \%)$ & $7(35.0 \%)$ \\
\hline High quality & $0(0.0 \%)$ & $2(10.0 \%)$ \\
\hline Avg. quality & $-0.38(0.07)$ & $-0.43(0.15)$ \\
\hline Avg. buyer earnings (all offers) & $9.65[0.95]$ & $7.84[1.28]$ \\
\hline Avg. seller earnings (all offers) & $5.88[0.92]$ & $7.23[1.89]$ \\
\hline Avg. total earnings (all offers) & $15.54[1.47]$ & $15.06[2.82]$ \\
\hline
\end{tabular}

${ }^{\wedge}$ We exclude one case in which the buyer received a very large negative payoff in the final period. Standard errors are in brackets. 
Table B5: Behavior in session 1 of the endogenous chat treatment

\begin{tabular}{|c|c|c|}
\hline Category & Rigid contract & Flexible contract \\
\hline Frequency & $29(26.4 \%)$ & $81(73.6 \%)$ \\
\hline Rejections & $9(23.7 \%)$ & $4(4.7 \%)$ \\
\hline Average P & $19.41[1.76]$ & $17.37[0.84]$ \\
\hline Average Q & - & $9.29[0.86]$ \\
\hline Low quality & $6(30.0 \%)$ & $8(10.4 \%)$ \\
\hline Normal quality & $3(15.0 \%)$ & $15(19.5 \%)$ \\
\hline High quality & $11(55.0 \%)$ & $54(70.1 \%)$ \\
\hline Avg. quality & $0.25[0.20]$ & $0.60[0.08]$ \\
\hline Avg. buyer earnings (all offers) & $10.83[0.58]$ & $15.59[1.45]$ \\
\hline Avg. seller earnings (all offers) & $16.00[2.03]$ & $21.54[0.93]$ \\
\hline Avg. total earnings (all offers) & $26.83[3.62]$ & $37.14[1.94]$ \\
\hline
\end{tabular}

Standard errors are in brackets.

Table B6: Behavior in session 2 of the endogenous chat treatment

\begin{tabular}{|c|c|c|}
\hline Category & Rigid contract & Flexible contract \\
\hline Frequency* & $12(11.1 \%)$ & $96(88.9 \%)$ \\
\hline Rejections & $6(50.0 \%)$ & $2(2.0 \%)$ \\
\hline Average P & $13.42[2.28]$ & $10.92[0.97]$ \\
\hline Average Q & - & $15.74[1.02]$ \\
\hline Low quality & $0(0.0 \%)$ & $5(5.3 \%)$ \\
\hline Normal quality & $4(66.7 \%)$ & $17(18.1 \%)$ \\
\hline High quality & $2(33.3 \%)$ & $72(76.6 \%)$ \\
\hline Avg. quality & $0.33[0.21]$ & $0.71[0.06]$ \\
\hline Avg. buyer earnings (all offers) & $14.42[3.63]$ & $18.39[0.79]$ \\
\hline Avg. seller earnings (all offers) & $7.92[3.78]$ & $20.81[0.95]$ \\
\hline Avg. total earnings (all offers) & $22.33[4.51]$ & $39.20[1.44]$ \\
\hline
\end{tabular}

* No contract was offered on two occasions. Standard errors are in brackets. 
Table B7: Behavior in session 3 of the endogenous chat treatment

\begin{tabular}{|c|c|c|}
\hline Category & Rigid contract & Flexible contract \\
\hline Frequency & $53(48.2 \%)$ & $57(51.8 \%)$ \\
\hline Rejections & $3(5.7 \%)$ & $6(10.5 \%)$ \\
\hline Average P & $25.91[0.85]$ & $19.23[1.04]$ \\
\hline Average Q & - & $7.92[1.17]$ \\
\hline Low quality & $3(6.0 \%)$ & $4(7.8 \%)$ \\
\hline Normal quality & $21(42.0 \%)$ & $15(29.4 \%)$ \\
\hline High quality & $26(52.0 \%)$ & $32(62.8 \%)$ \\
\hline Avg. quality & $0.46[0.09]$ & $0.55[0.09]$ \\
\hline Avg. buyer earnings (all offers) & $14.47[1.24]$ & $13.86[1.41]$ \\
\hline Avg. seller earnings (all offers) & $18.94[1.69]$ & $19.19[1.23]$ \\
\hline Avg. total earnings (all offers) & $33.42[2.37]$ & $33.05[2.19]$ \\
\hline
\end{tabular}

Standard errors are in brackets.

Table B8: Behavior in session 4 of the endogenous chat treatment

\begin{tabular}{|c|c|c|}
\hline Category & Rigid contract & Flexible contract \\
\hline Frequency & $15(15.4 \%)$ & $93(84.6 \%)$ \\
\hline Rejections & $2(11.8 \%)$ & $0(0.0 \%)$ \\
\hline Average P & $25.24[2.08]$ & $21.30[0.32]$ \\
\hline Average Q & - & $6.52[0.58]$ \\
\hline Low quality & $4(26.7 \%)$ & $3(3.2 \%)$ \\
\hline Normal quality & $5(33.3 \%)$ & $14(15.1 \%)$ \\
\hline High quality & $6(40.0 \%)$ & $76(81.7 \%)$ \\
\hline Avg. quality & $0.13[0.22]$ & $0.78[0.05]$ \\
\hline Avg. buyer earnings (all offers) & $8.88[2.59]$ & $18.80[0.86]$ \\
\hline Avg. seller earnings (all offers) & $17.00[1.16]$ & $21.65[2.80]$ \\
\hline Avg. total earnings (all offers) & $25.88[4.39]$ & $40.44[1.27]$ \\
\hline
\end{tabular}

Standard errors are in brackets. 
Table B9: Behavior in session 1 of the exogenous rigid no-communication treatment

\begin{tabular}{|c|c|}
\hline Category & Rigid contract \\
\hline Frequency* & $109(100 \%)$ \\
\hline Rejections & $36(33.0 \%)$ \\
\hline Average P & $14.09[0.62]$ \\
\hline Average Q & - \\
\hline Low quality & $29(39.7 \%)$ \\
\hline Normal quality & $41(56.2 \%)$ \\
\hline High quality & $3(4.1 \%)$ \\
\hline Avg. quality & $-0.36[0.07]$ \\
\hline Avg. buyer earnings (all offers) & $7.13[0.90]$ \\
\hline Avg. seller earnings (all offers) & $13.08[1.17]$ \\
\hline Avg. total earnings (all offers) & $20.21[1.48]$ \\
\hline
\end{tabular}

* No contract was offered on one occasion. Standard errors are in brackets.

Table B10: Behavior in session 2 of the exogenous rigid no-communication treatment

\begin{tabular}{|c|c|}
\hline Category & Rigid contract \\
\hline Frequency* & $107(100 \%)$ \\
\hline Rejections & $40(37.4 \%)$ \\
\hline Average P & $14.07[0.57]$ \\
\hline Average Q & - \\
\hline Low quality & $18(26.9 \%)$ \\
\hline Normal quality & $44(65.7 \%)$ \\
\hline High quality & $5(7.5 \%)$ \\
\hline Avg. quality & $-0.19[0.07]$ \\
\hline Avg. buyer earnings (all offers) & $12.11[0.96]$ \\
\hline Avg. seller earnings (all offers) & $7.36[0.79]$ \\
\hline Avg. total earnings (all offers) & $19.47[1.34]$ \\
\hline
\end{tabular}

* No contract was offered on three occasions. Standard errors are in brackets. 
Table B11: Behavior in session 3 of the exogenous rigid no-communication treatment

\begin{tabular}{|c|c|}
\hline Category & Rigid contract \\
\hline Frequency & $110(100 \%)$ \\
\hline Rejections & $29(26.4 \%)$ \\
\hline Average P & $16.53[0.45]$ \\
\hline Average Q & - \\
\hline Low quality & $23(28.4 \%)$ \\
\hline Normal quality & $52(64.2 \%)$ \\
\hline High quality & $6(7.4 \%)$ \\
\hline Avg. quality & $-0.21[0.06]$ \\
\hline Avg. buyer earnings (all offers) & $11.55[0.94]$ \\
\hline Avg. seller earnings (all offers) & $10.55[0.90]$ \\
\hline Avg. total earnings (all offers) & $22.10[1.40]$ \\
\hline
\end{tabular}

Standard errors are in brackets.

Table B12: Behavior in session 4 of the exogenous rigid no-communication treatment

\begin{tabular}{|c|c|}
\hline Category & Rigid contract \\
\hline Frequency & $110(100 \%)$ \\
\hline Rejections & $47(42.7 \%)$ \\
\hline Average P & $14.62[0.40]$ \\
\hline Average Q & - \\
\hline Low quality & $16(25.4 \%)$ \\
\hline Normal quality & $46(73.0 \%)$ \\
\hline High quality & $1(1.6 \%)$ \\
\hline Avg. quality & $-0.24[0.06]$ \\
\hline Avg. buyer earnings (all offers) & $11.04[0.86]$ \\
\hline Avg. seller earnings (all offers) & $8.67[0.81]$ \\
\hline Avg. total earnings (all offers) & $19.71[1.28]$ \\
\hline
\end{tabular}

Standard errors are in brackets. 
Table B13: Behavior in session 1 of the exogenous flex no-communication treatment

\begin{tabular}{|c|c|}
\hline Category & Flexible contract \\
\hline Frequency* & $109(100 \%)$ \\
\hline Rejections & $33(30.3 \%)$ \\
\hline Average P & $15.17[0.76]$ \\
\hline Average Q & $3.62[0.50]$ \\
\hline Low quality & $26(34.2 \%)$ \\
\hline Normal quality & $41(54.0 \%)$ \\
\hline High quality & $9(11.8 \%)$ \\
\hline Avg. quality & $-0.22[0.07]$ \\
\hline Avg. buyer earnings (all offers) & $9.25[0.96]$ \\
\hline Avg. seller earnings (all offers) & $10.75[1.09]$ \\
\hline Avg. total earnings (all offers) & $20.00[1.59]$ \\
\hline
\end{tabular}

- No contract was offered on one occasion. Standard errors are in brackets.

Table B14: Behavior in session 2 of the exogenous flex no-communication treatment

\begin{tabular}{|c|c|}
\hline Category & Flexible contract \\
\hline Frequency & $110(100 \%)$ \\
\hline Rejections & $40(36.4 \%)$ \\
\hline Average P & $13.57[0.63]$ \\
\hline Average Q & $3.30[0.76]$ \\
\hline Low quality & $33(47.1 \%)$ \\
\hline Normal quality & $31(44.3 \%)$ \\
\hline High quality & $6(8.6 \%)$ \\
\hline Avg. quality & $-0.39[0.08]$ \\
\hline Avg. buyer earnings (all offers) & $8.17[0.90]$ \\
\hline Avg. seller earnings (all offers) & $8.11[0.93]$ \\
\hline Avg. total earnings (all offers) & $16.28[1.40]$ \\
\hline
\end{tabular}

Standard errors are in brackets. 
Table B15: Behavior in session 3 of the exogenous flex no-communication treatment

\begin{tabular}{|c|c|}
\hline Category & Flexible contract \\
\hline Frequency & $110(100 \%)$ \\
\hline Rejections & $26(39.7 \%)$ \\
\hline Average P & $14.48[0.63]$ \\
\hline Average Q & $4.88[1.12]$ \\
\hline Low quality & $20(23.8 \%)$ \\
\hline Normal quality & $50(59.5 \%)$ \\
\hline High quality & $14(16.7 \%)$ \\
\hline Avg. quality & $-0.07[0.07]$ \\
\hline Avg. buyer earnings (all offers) & $11.40[1.02]$ \\
\hline Avg. seller earnings (all offers) & $13.84[1.33]$ \\
\hline Avg. total earnings (all offers) & $25.24[1.63]$ \\
\hline
\end{tabular}

Standard errors are in brackets.

Table B16: Behavior in session 4 of the exogenous flex no-communication treatment

\begin{tabular}{|c|c|}
\hline Category & Rigid contract \\
\hline Frequency & $110(100 \%)$ \\
\hline Rejections & $21(19.1 \%)$ \\
\hline Average P & $12.37[0.47]$ \\
\hline Average Q & $2.90(0.41)$ \\
\hline Low quality & $29(32.6 \%)$ \\
\hline Normal quality & $52(58.4 \%)$ \\
\hline High quality & $8(9.0 \%)$ \\
\hline Average quality & $-0.24[0.06]$ \\
\hline Avg. buyer earnings (all offers) & $9.67[1.10]$ \\
\hline Avg. seller earnings (all offers) & $11.72[0.87]$ \\
\hline Avg. total earnings (all offers) & $21.39[1.56]$ \\
\hline
\end{tabular}

Standard errors are in brackets. 
Table B17: Behavior in session 1 of the exogenous rigid chat treatment

\begin{tabular}{|c|c|}
\hline Category & Rigid contract \\
\hline Frequency & $110(100 \%)$ \\
\hline Rejections & $12(10.9 \%)$ \\
\hline Average P & $27.37[0.81]$ \\
\hline Average Q & - \\
\hline Low quality & $4(4.1 \%)$ \\
\hline Normal quality & $30(30.6 \%)$ \\
\hline High quality & $64(65.3 \%)$ \\
\hline Avg. quality & $0.61[0.06]$ \\
\hline Avg. buyer earnings (all offers) & $13.03[0.85]$ \\
\hline Avg. seller earnings (all offers) & $22.35[1.11]$ \\
\hline Avg. total earnings (all offers) & $35.38[1.38]$ \\
\hline
\end{tabular}

Standard errors are in brackets.

Table B18: Behavior in session 2 of the exogenous rigid chat treatment

\begin{tabular}{|c|c|}
\hline Category & Rigid contract \\
\hline Frequency & $110(100 \%)$ \\
\hline Rejections & $15(13.6 \%)$ \\
\hline Average P & $23.28[0.68]$ \\
\hline Average Q & - \\
\hline Low quality & $14(14.7 \%)$ \\
\hline Normal quality & $25(26.3 \%)$ \\
\hline High quality & $56(58.9 \%)$ \\
\hline Avg. quality & $0.44[0.08]$ \\
\hline Avg. buyer earnings (all offers) & $14.11[1.13]$ \\
\hline Avg. seller earnings (all offers) & $18.80[1.10]$ \\
\hline Avg. total earnings (all offers) & $32.91[1.69]$ \\
\hline
\end{tabular}

Standard errors are in brackets. 
Table B19: Behavior in session 3 of the exogenous rigid chat treatment

\begin{tabular}{|c|c|}
\hline Category & Rigid contract \\
\hline Frequency & $110(100 \%)$ \\
\hline Rejections & $22(20.0 \%)$ \\
\hline Average P & $21.17[1.20]$ \\
\hline Average Q & - \\
\hline Low quality & $24(27.3 \%)$ \\
\hline Normal quality & $29(32.9 \%)$ \\
\hline High quality & $35(39.8 \%)$ \\
\hline Avg. quality & $0.12[0.09]$ \\
\hline Avg. buyer earnings (all offers) & $9.84[1.18]$ \\
\hline Avg. seller earnings (all offers) & $15.67[1.40]$ \\
\hline Avg. total earnings (all offers) & $25.51[1.68]$ \\
\hline
\end{tabular}

Standard errors are in brackets.

Table B20: Behavior in session 4 of the exogenous rigid chat treatment

\begin{tabular}{|c|c|}
\hline Category & Rigid contract \\
\hline Frequency & $110(100 \%)$ \\
\hline Rejections & $14(12.7 \%)$ \\
\hline Average P & $19.91[0.78]$ \\
\hline Average Q & - \\
\hline Low quality & $21(21.9 \%)$ \\
\hline Normal quality & $40(41.7 \%)$ \\
\hline High quality & $35(36.5 \%)$ \\
\hline Avg. quality & $0.15[0.08]$ \\
\hline Avg. buyer earnings (all offers) & $13.33[1.10]$ \\
\hline Avg. seller earnings (all offers) & $12.94[1.16]$ \\
\hline Avg. total earnings (all offers) & $26.26[1.72]$ \\
\hline
\end{tabular}

Standard errors are in brackets. 
Table B21: Behavior in session 1 of the exogenous flex chat treatment

\begin{tabular}{|c|c|}
\hline Category & Flexible contract \\
\hline Frequency & $110(100 \%)$ \\
\hline Rejections & $4(3.6 \%)$ \\
\hline Average P & $13.98[0.57]$ \\
\hline Average Q & $12.05(0.76)$ \\
\hline Low quality & $7(6.6 \%)$ \\
\hline Normal quality & $20(18.9 \%)$ \\
\hline High quality & $79(74.5 \%)$ \\
\hline Avg. quality & $0.68[0.06]$ \\
\hline Avg. buyer earnings (all offers) & $18.04[0.82]$ \\
\hline Avg. seller earnings (all offers) & $19.95[0.88]$ \\
\hline Avg. total earnings (all offers) & $37.99[1.44]$ \\
\hline
\end{tabular}

Standard errors are in brackets.

Table B22: Behavior in session 2 of the exogenous flex chat treatment

\begin{tabular}{|c|c|}
\hline Category & Flexible contract \\
\hline Frequency & $110(100 \%)$ \\
\hline Rejections & $4(3.6 \%)$ \\
\hline Average P & $14.74[0.60]$ \\
\hline Average Q & $9.88[0.76]$ \\
\hline Low quality & $9(8.5 \%)$ \\
\hline Normal quality & $24(22.6 \%)$ \\
\hline High quality & $73(68.9 \%)$ \\
\hline Avg. quality & $0.60[0.06]$ \\
\hline Avg. buyer earnings (all offers) & $18.19[0.92]$ \\
\hline Avg. seller earnings (all offers) & $18.84[0.92]$ \\
\hline Avg. total earnings (all offers) & $37.03[1.47]$ \\
\hline
\end{tabular}

Standard errors are in brackets. 
Table B23: Behavior in session 3 of the exogenous flex chat treatment

\begin{tabular}{|c|c|}
\hline Category & Flexible contract \\
\hline Frequency & $110(100 \%)$ \\
\hline Rejections & $5(4.6 \%)$ \\
\hline Average P & $10.64[0.63]$ \\
\hline Average Q & $15.05[0.83]$ \\
\hline Low quality & $18(17.1 \%)$ \\
\hline Normal quality & $12(11.4 \%)$ \\
\hline High quality & $75(71.4 \%)$ \\
\hline Avg. quality & $0.54[0.08]$ \\
\hline Avg. buyer earnings (all offers) & $15.87[0.99]$ \\
\hline Avg. seller earnings (all offers) & $18.15[0.95]$ \\
\hline Avg. total earnings (all offers) & $34.02[1.61]$ \\
\hline
\end{tabular}

Standard errors are in brackets.

Table B24: Behavior in session 4 of the exogenous flex chat treatment

\begin{tabular}{|c|c|}
\hline Category & Flexible contract \\
\hline Frequency & $110(100 \%)$ \\
\hline Rejections & $5(4.6 \%)$ \\
\hline Average P & $13.21[0.58]$ \\
\hline Average Q & $12.21[0.77]$ \\
\hline Low quality & $17(16.2 \%)$ \\
\hline Normal quality & $29(27.6 \%)$ \\
\hline High quality & $59(56.2 \%)$ \\
\hline Avg. quality & $0.42[0.07]$ \\
\hline Avg. buyer earnings (all offers) & $13.98[1.14]$ \\
\hline Avg. seller earnings (all offers) & $19.11[1.03]$ \\
\hline Avg. total earnings (all offers) & $33.08[1.71]$ \\
\hline
\end{tabular}

Standard errors are in brackets. 